\title{
Mídia, consumo e publicidade: refletindo sobre o brincar na educação infantil
}

\author{
Fernanda Theodoro Roveri* \\ Ana Carolina Pereira Martins dos Santos*
}

\section{Resumo}

Este artigo discute a influência da publicidade na infância a partir do relato de uma prática pedagógica realizada no ano de 2013 em escolas de educação infantil da rede municipal de Campinas, São Paulo, com crianças de 2 a 6 anos de idade. $O$ objetivo desta análise é repensar a função da escola diante de uma invasão massiva da publicidade infantil, tomando como objeto de reflexão o "dia do brinquedo", prática muito comum em instituições de educação infantil. Neste texto, são relatadas algumas experiências que contribuíram para que as crianças vivenciassem a infância em suas múltiplas linguagens. O propósito não é demarcar e restringir as escolhas pedagógicas, mas, sim, suscitar outras buscas por alternativas que articulem reflexões em torno do consumismo e do espaço do brincar. Como resultado, conclui-se que uma das possibilidades para a superação da lógica do consumismo é propiciar às crianças experiências significativas, que também sensibilizem a comunidade e os profissionais da escola.

Palavras-chave: Brincar. Consumismo. Educação infantil. Infância.

\section{Introdução}

Um olhar para a publicidade infantil pode nos ajudar a compreender as expectativas sociais em relação ao comportamento das crianças e os modos como elas são educadas em nossa sociedade. Tomando como ponto de partida a concepção de que os artefatos culturais atravessam os currículos escolares (GIROUX, 1995), elegemos a publicidade dirigida às crianças para analisarmos o brincar na educação infantil.

\author{
Recebido: 14/04/2015 - Aprovado: 11/11/2015 \\ http://dx.doi.org/10.5335/rep.v23i1.6362
}

Doutora em Educação pela Unicamp. Professora de educação infantil na rede municipal de Campinas, SP. Professora do curso de Pedagogia da lescamp, Campinas, SP. Membro do grupo de pesquisa FOCUS, FE/Unicamp. E-mail: ferdth@yahoo.com.br

** Pedagoga pela Universidade de São Paulo. Professora de educação infantil da rede municipal de Campinas, SP. E-mail: anacarol_pedagogia@yahoo.com.br 
Consideramos que a escola está imersa em uma rede de circularidade de culturas. Essas culturas configuram os modos de vivermos e os sentidos que damos às nossas ações. Estamos inseridos em mundos cada vez mais múltiplos e virtuais, marcados pela velocidade e pela fluidez. Conforme analisa Hall:

Toda a nossa conduta e todas as nossas ações são moldadas, influenciadas e, desta forma, reguladas normativamente pelos significados culturais. Uma vez que a cultura regula as práticas e condutas sociais, neste sentido, então, é profundamente importante quem regula a cultura. A regulação da cultura e a regulação através da cultura são, desta forma, íntima e profundamente interligadas (1997, p. 41, grifo do autor).

A regulação das pessoas, assim, não acontece apenas nos espaços institucionais educativos. Existe uma pedagogia cultural, formada por filmes, revistas, músicas, videogames, brinquedos, lojas, etc., por meio da qual os mecanismos de poder se organizam. Esse poder, muitas vezes, está camuflado sob a aura da fantasia e do divertimento. Henry Giroux (1995), ao aventurar-se no contraditório mundo da Disney, confessa que, a seu ver, as animações feitas para crianças pareciam "bons" veículos, saudáveis, de imaginação e fantasia. No entanto, o autor acaba reconhecendo que os estudos culturais não mostraram interesse na cultura infantil, sendo necessário compreender os filmes animados como elementos persuasivos, "máquinas de ensinar" que ultrapassam as fronteiras do divertimento (GIROUX, 1995, p. 51).

Assim, é notável que os artefatos da indústria cultural, de alguma maneira, tenham adentrado também a escola, ensinando, educando e produzindo sujeitos. É necessário, pois, uma prática docente voltada à percepção das diferentes marcas culturais presentes nos currículos (PARAÍSO, 2010). Garantir o respeito à igualdade de direitos, à infância e ao lúdico pressupõe um olhar pedagógico de investigação, de análise e de reinvenção do cotidiano.

Analisaremos, primeiramente, a influência da publicidade na educação das crianças, apresentando algumas discussões sobre a infância na sociedade de consumo. Em seguida, apresentaremos nossas experiências desenvolvidas no espaço-tempo do brincar, em duas instituições municipais de educação infantil de Campinas, São Paulo, no ano de 2013, com crianças de 2 a 6 anos de idade. O objetivo é refletir sobre possíveis práticas pedagógicas que contribuam para a vivência das diversas linguagens infantis, valorizando o espaço do brincar como suporte para a imaginação, a criação e as interações dos sujeitos envolvidos no processo educativo.

Fazemos, então, o convite à leitura recorrendo ao desafio lançado por Moreira (1997), quando nos instiga a pensar o ensino e a docência orientados a uma visão de futuro e atrelados à construção de um mundo social mais justo. Para isso, é preciso desafiar os limites do estabelecido e esboçar coletivamente um novo horizonte de 
possibilidades. Esse é, sem dúvida, o caráter político da educação e da profissão docente. Seria possível, então, questionarmos: como tornar o cotidiano da educação infantil um espaço aberto às reinvenções?

\section{Publicidade: a conquista da infância}

Os estudos de Roveri $(2012,2014)$ analisam a década de 1950 como um período de grandes transformações na vida cotidiana, sobretudo das populações situadas nos centros urbanos. As relações sociais foram marcadas pela expressão do ideal de um novo estilo de vida, do qual faziam parte as novas necessidades de consumo. A autora descreve que a televisão iniciava sua transmissão no país nesse período e, pouco a pouco, consolidava-se como um expressivo veículo dirigido não apenas aos adultos, mas também ao público infantil.

A publicidade da década de 1950, presente em diferentes meios de comunicação, fazia parte dos cotidianos das sociedades urbanas e industriais. Os fabricantes e publicitários percebiam a criança como potencial consumidora de alimentos, livros, revistas, produtos de higiene e brinquedos. As propagandas tinham como alvo, em especial, a mulher, responsável pela escolha do que seria consumido por sua família (MARTINI, 2011). Inúmeras imagens de crianças - que antes eram usadas como atrativos de venda ao público adulto - voltaram-se, paulatinamente, à atenção da própria criança.

Logo, os veículos de comunicação, além de expressarem o interesse dos publicitários em vender seus produtos, contribuíram para dar voz de consumo às crianças. Elas são vistas como uma oportunidade comercial para a fabricação e venda de produtos, tornando-se responsável por inúmeras decisões de compra no lugar dos adultos. As escolhas do vestuário, dos brinquedos e de outros itens de consumo cada vez mais fazem parte das preocupações infantis (ROVERI, 2012). Poderíamos dizer, assim, que as transformações ocorridas nas sociedades de consumo nas últimas décadas abarcaram impactos significativos no conceito de infância.

Ao analisar os mecanismos de sedução e de perpetuação das marcas, Linn observa que as corporações "buscam estabelecer um vínculo de lealdade às marcas de seus produtos e serviços que vá do "berço ao túmulo"' (2006, p. 21), ou seja, a lógica das empresas consiste em atingir o consumidor desde a tenra idade, pois assim terão mais garantias de sucesso e de permanência de seus produtos. Uma das estratégias, para isso, é a veiculação de personagens animados, ídolos e ícones às mercadorias, artifícios para uma venda mais eficaz.

Dessa maneira, vê-se, por exemplo, alimentos com figuras de desenhos animados que incentivam uma "alimentação divertida"; parques temáticos que convidam 
a criança a desfrutar de um ambiente de sonho e magia; ídolos musicais que se apresentam como modelos de prestígio e sucesso para crianças e adolescentes; filmes que imediatamente tornam-se produtos e brinquedos, que, com o lançamento de outra novidade, logo ficarão obsoletos.

É importante destacarmos que brinquedos e outros produtos destinados às crianças não são objetos de pureza, inocência e encantamento, mas mercadorias de consumo cujos fabricantes competem pela conquista da infância. Essas criações, voltadas exclusivamente para crianças, têm produzido uma cultura infantil atrelada ao consumo, o que Steinberg e Kincheloe (2001) denominaram de "construção corporativa da infância".

Os comportamentos, as sensações, as experiências e as diversas formas de convívio das crianças são cada vez mais afetados pelos apelos publicitários (LINN, 2006; SCHOR, 2009). As crianças, expostas aos estímulos da mídia, vivenciam infâncias também marcadas por questões como a obesidade infantil, a erotização precoce, o estresse familiar, a violência doméstica e a redução das brincadeiras criativas.

A publicidade age nas emoções afetando as sensibilidades infantis ao misturar a fantasia e a realidade. Com isso, vincula-se o desenvolvimento da personalidade àquilo que é adquirido. Apresenta-se à criança não o produto em si, mas o que está por trás da compra, ou seja, comprar a sandália de um determinado personagem radical significa ter superpoderes, por exemplo. As propagandas estimulam as crianças a consumirem, difundindo-lhes a mensagem que comprando serão felizes e se sentirão bem. A personalidade é, então, terceirizada a um produto (TOLOTTI, 2012).

Nesse sentido, pode-se dizer que a publicidade é sedutora, na medida em que filmes, desenhos, comerciais e produtos despertam um desejo de consumo. Bourdieu (2007) afirma que o consumidor, ao adquirir um produto e identificar-se com ele, contribui para a produção do que consome. De acordo com o autor, a formação do gosto está associada aos usos sociais de um produto e à maneira como este é reconhecido e apreciado pelo público. Assim, os gostos funcionam como "marcadores privilegiados de classe" e são formados por um processo de educação familiar, escolar e de outras instâncias. Nesse processo, reforça-se o que é aceitável socialmente e desestimula-se o que não é (ROVERI, 2014).

Compreendemos, portanto, que a formação de um gosto faz parte de um processo educativo. A indústria do entretenimento infantil toma para si a formação desse gosto, carregando seus produtos de significados que interferem nas sensibilidades infantis. A escola, por sua vez, também participa dessa formação, pois tanto 
legitima o que é trazido pela mídia quanto oferece repertórios variados por meio dos quais as crianças constroem saberes e atribuem novos sentidos ao conhecimento.

Sabemos que criar cultura é essencialmente humano, e, de acordo com Prado (1999), crianças também são sujeitos portadores de cultura, pois é pela mediação com o outro que se constrói um sistema de comunicação, significados e expressões específicas. Nesse aspecto, consideramos a importância de repensarmos a função da escola diante da invasão massiva da publicidade dirigida ao público infantil.

Com o intuito de abrirmos possibilidades de diálogos e intervenções, propomos, a seguir, uma reflexão sobre nossas práticas pedagógicas na educação infantil, apresentando dois projetos desenvolvidos com crianças. O objetivo deles foi a valorização da cultura infantil e a ampliação do repertório de brincadeiras, músicas e outras vivências coletivas. Sugerimos, então, um olhar reflexivo para as questões: Que espaço é este de onde falamos? Qual o compromisso a ser assumido por todos aqueles que trabalham com as crianças?

\section{Repensando o dia do brinquedo}

Em nossa escola, todas as sextas-feiras, havia uma prática chamada dia do brinquedo, momento no qual as crianças traziam de suas casas um brinquedo para se divertirem com os amigos. Entretanto, percebíamos que poucas crianças aproveitavam tal momento para interagir, dividir e trocar seus pertences. Além disso, muitas famílias ordenavam aos seus filhos que não quebrassem, perdessem ou, até mesmo, que não emprestassem aos colegas. Sendo a maioria dos brinquedos eletrônicos e jogos individuais, a interação entre as crianças ficou cada vez mais comprometida.

Esse fato nos fez perceber, conforme evidenciado por Barthes (1982), que as crianças tornaram-se muito mais proprietárias dos brinquedos do que criadoras. A passividade no ato de brincar ocorre, sobretudo, porque a criança possui muitos brinquedos "fornecidos prontos: ela só tem de utilizá-los, nunca há nenhum caminho a percorrer" (1982, p. 41). Considerando que as crianças poderiam percorrer outros caminhos se lhes fossem oferecidas variadas formas de expressão, diferentemente daquelas estabelecidas, sobretudo pela cultura midiática, repensamos nossas práticas em relação aos momentos de brincar.

O processo de reflexão envolveu outras professoras que também vivenciavam esses dilemas em suas escolas. Ao trocarmos experiências em nossas e em outras unidades de educação infantil, em seminários temáticos e em reuniões pedagógicas, conhecemos propostas diferenciadas que buscavam ressignificar o dia do brinquedo, dentre as quais destacamos a da brincadeira interativa. 
O objetivo dessa proposta era construir novos e diferentes momentos de brincar, que pudessem envolver as crianças e também seus familiares. Ao invés de trazerem de casa o brinquedo que quisessem, combinamos com as crianças uma brincadeira para ser realizada coletivamente. Em seguida, pensamos nos materiais necessários para realizá-la e, então, enviamos um bilhete informando aos familiares qual seria a contribuição para a brincadeira interativa da semana: um objeto qualquer, como utensílio de cozinha, sucatas, algum adereço, folhas e sementes, dentre outros materiais. Muitas possibilidades de brincar foram surgindo, como o dia da sorveteria, o do supermercado, construções com caixas de papelão, acampamento, zoológico, floresta, marcenaria, viagem espacial, etc.

Um dos grandes desafios aos educadores é pensar uma prática pedagógica que supere a lógica do consumo e entretenimento. Quando desejam que as atividades com as crianças sejam divertidas e prazerosas, muitos não imaginam outra forma que não a proposta pelas mídias. Conforme discutem Souza e Salgado,

[...] o grande desafio que se coloca hoje para pais e educadores é o de como lançar novas questões frente às semióticas que se estabelecem como globais para que as crianças possam experimentar e criar outras formas de expressão mais livres e variadas, recuperando a necessária diversidade cultural nos modos de ser, agir, pensar e falar sobre as experiências coletiva e subjetiva. Uma política educativa que se proponha a um engajamento com outras possibilidades de constituição ética e estética do desejo na formação das crianças deve se comprometer a criar espaços alternativos de acesso das crianças e dos adultos a uma pluralidade de produções culturais, pautadas na diversidade de experiências humanas (2008, p. 220).

Desta forma, com o propósito de criar novos espaços para as experiências e produções das crianças e dos adultos envolvidos no processo educativo, realizamos em nossas escolas um trabalho a partir de nossas memórias e de nosso repertório, que, juntamente com as crianças, foi apropriado e reinventado. A seguir, descrevemos as experiências vividas a partir do desafio de propor situações novas e ricas para o momento do brincar. Não se trata de oferecer um modelo ideal de prática educativa, mas, sim, de abrir possibilidades para que outros caminhos sejam construídos e redesenhados com crianças e adultos.

\section{Hoje tem feira de trocas!}

A partir da reformulação do dia do brinquedo, desenvolvemos uma importante atividade durante $o$ ano: a Feira de troca de brinquedos. ${ }^{1}$ Mensalmente, cada turma confecciona um brinquedo ou objeto com material reciclável em sua sala de aula (Figura 1). Ao final do mês, em uma data agendada, esses materiais são expostos 
no galpão da escola para que a criança leve o objeto confeccionado por ela, observe o que seus amigos fizeram e solicite a troca.

Figura 1 - Brinquedos confeccionados com materiais recicláveis em uma das feiras de trocas
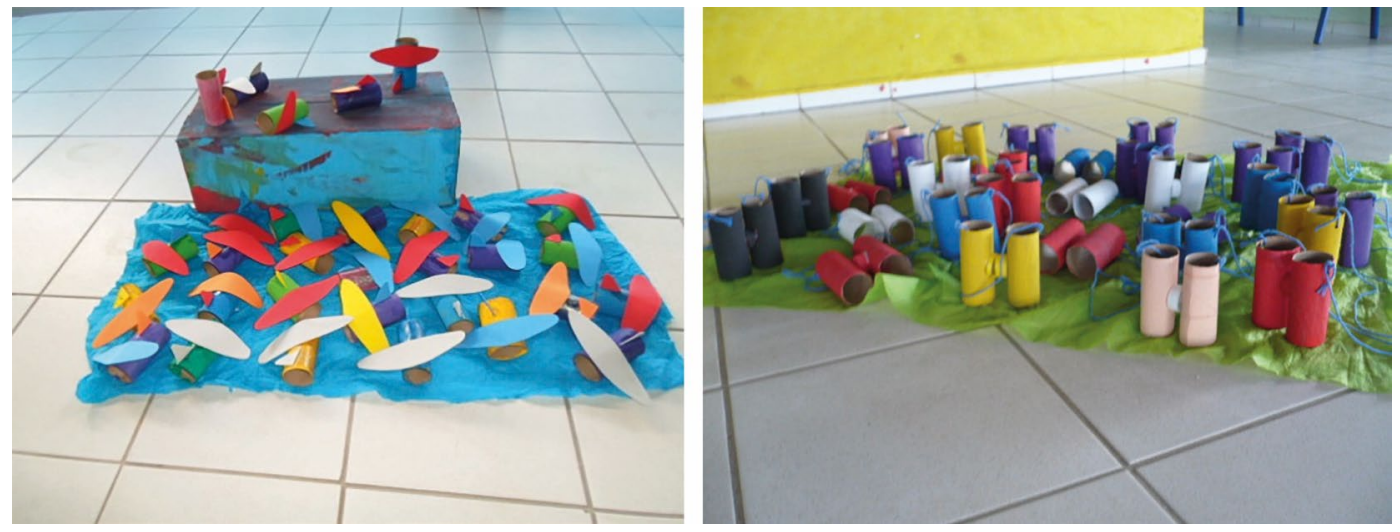

Fonte: elaboração das autoras, 2013.

Nesse processo, mais importante do que o brinquedo em si é a novidade, a diversão e as interações que ele proporciona. Percebemos o valor dado pelas crianças àquilo que constroem e a dedicação com que o fazem. A empolgação de trocar seu objeto com o amigo evidencia que a importância está no processo de mostrar e reconhecer suas capacidades inventivas, além do afeto na partilha e na troca do que foi produzido.

Além disso, por intermédio das feiras de trocas, as crianças são estimuladas a pensar sobre seus brinquedos: será que para se divertirem precisam apenas de brinquedos eletrônicos ou podem vivenciar prazerosas brincadeiras com um brinquedo confeccionado por elas próprias?

Outras reflexões em relação ao consumismo a que estão expostas diariamente foram despertadas nas famílias. Por intermédio dos relatos dos adultos, pudemos notar que as crianças estavam valorizando as sucatas que seriam jogadas no lixo, pois com tal material poderiam confeccionar um brinquedo. Esses relatos abriram espaço para que iniciássemos uma conversa sobre a preservação do meio ambiente e o reaproveitamento de materiais, repensando os excessos e evitando os desperdícios.

A última feira de trocas do ano aconteceu às vésperas das comemorações do Dia das Crianças, data marcadamente comercial e permeada pelos excessos de publicidade, vendas e desejos. Essa data foi escolhida justamente para provocar a reflexão das famílias e oferecer um outro olhar sobre essa comemoração. 
As famílias foram convidadas a participar juntamente com seus filhos trazendo de casa um brinquedo que não lhes interessava mais e que poderia realizar os desejos de outras crianças (Figura 2). Notamos que o evento foi uma oportunidade de aproximação das famílias e de valorização das relações por meio das brincadeiras.

Figura 2 - Brinquedos enviados pelas famílias para troca
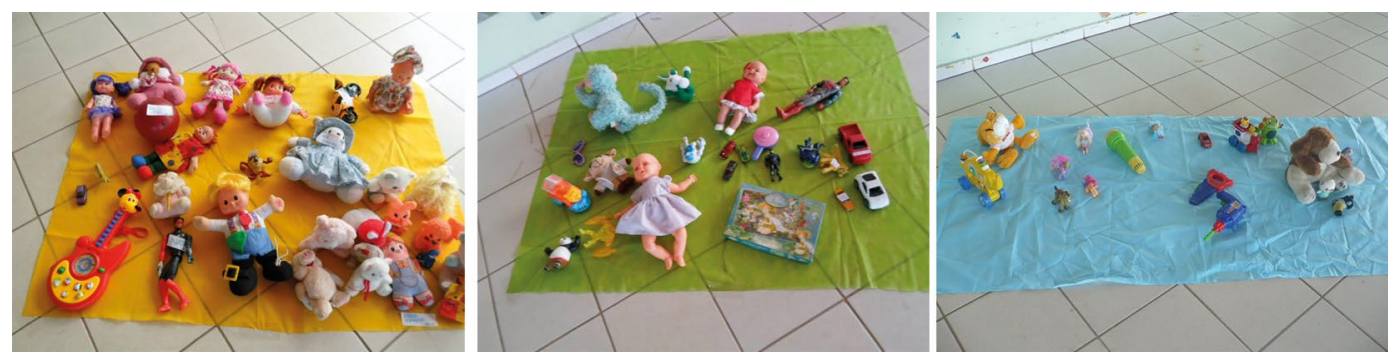

Fonte: elaboração das autoras, 2013.

Concordando com Zanolla (2007) e Kishimoto (1996), acreditamos que cabe à escola ampliar o repertório cultural das crianças e, através das brincadeiras, dar asas à sua imaginação. E, ainda, de acordo com Weiss:

[...] recuperar o espaço lúdico através da construção de brinquedos significa não apenas considerar o objeto/brinquedo em si, mas aquilo a que ele possa se remeter: um pedaço, um fragmento do tempo/espaço da infância... presente no universo adulto. Recuperar, não a criança, que seria utopia, mas o espírito da criança, a liberdade da criança ao descobrir o mundo pela primeira vez (1997, p. 18).

Esse pode ser um dos caminhos para que a escola propicie outras possibilidades de diversão às crianças, não se limitando ao que já é conhecido, mas promovendo novos espaços para a criação infantil (OSTETTO, 2004).

\section{Brinquedos, histórias e memórias}

Outra proposta desenvolvida com as crianças durante o ano foi a construção de brinquedos a partir de elementos da natureza, como folhas, flores, sementes, gravetos e pedras. Frutos da criação humana, tais brinquedos são objetos de nossas memórias e descobertas; suas cores, formas, texturas, consistências e cheiros proporcionam ricas experiências e possibilidades inventivas.

Apresentamos ao grupo diversas sementes de árvores de nosso entorno, que também faziam parte de nosso cotidiano, com suas sombras, seus pássaros e sua vida. Assim, rapidamente as crianças aprenderam a nomear a flora local: Jacaran- 
dá, Jequitibá, Pata de vaca, Tipuana, Flamboyant, Chapéu de praia, dentre outras espécies.

A descoberta das folhas e sementes propiciou momentos ricos de manipulação e de movimentos: havia sementes que nos impulsionavam a pisoteá-las e ouvir seus estalos; outras, arremessadas ao ar, nos faziam rodopiar também; algumas interessantíssimas, ao serem abertas, revelavam segredos escondidos... Muitas se misturaram às receitas de bolos de areia que fazíamos no parque, outras se transformaram em helicópteros que voavam, em chocalhos, bonecos, etc. Brincadeiras que também fizeram parte de nossas infâncias, de nossos passeios aos bosques e parques da cidade, de nossas vivências rodeadas de árvores, na cidade ou no campo.

Cada semente era apresentada às crianças com uma história, uma música, algo que permitia imaginar, atribuir sentidos, desmanchar ou criar personagens, como fizemos com as sementes do Jacarandá-Mimoso, transformadas em coloridos sapos de bocas abertas.

Assim, com esses elementos da natureza, inúmeros brinquedos eram criados e as crianças os levavam para suas casas. Nesse espaço de convívio com adultos, outras memórias e histórias de pessoas que relembravam suas criações durante a infância se entrelaçaram e juntavam-se às nossas experiências, revelando que construir brinquedos, assim como "contar e inventar histórias oralmente, ou escrevê-las, são coisas que exigem pouquíssimos meios materiais, a voz ou papel e lápis, e são em princípio, possíveis a todos" (ALMEIDA, 2012, p. 25).

Particularmente, citamos algumas vivências que nos mostram o envolvimento das famílias no processo de imaginação, tais como: a iniciativa do pai de uma criança, que recolheu sementes de Pau-Brasil encontradas em seu local de trabalho e trouxe para a escola, juntamente com uma carta e uma pesquisa explicativas à turma; algumas crianças levaram à escola suas coleções de objetos indígenas feitos com variados materiais da natureza; o irmão mais velho de uma criança foi à escola tocar berimbau e nos ensinar a cantar a música Pisei na folha seca, por meio da qual brincamos de pisar na semente da árvore Pata de vaca, produzindo divertidos estalos.

Ao final desse trabalho, propusemos uma feira de exposições de brinquedos feitos pelas crianças e pelos familiares: brinquedos costurados, feitos com madeira, sucata, sementes... objetos imaginados e feitos à mão. Expô-los foi como abrir uma caixa mágica, mostrar nossas criações, coisas que não existem para serem vendidas. Um mundo rico de imaginação, de histórias e de criação abriu-se para o grupo e povoou nossa escola durante todas as estações e todas as floradas que, a partir daquele momento, já nos eram familiares. 
Figura 3 - Brinquedos feitos com sementes

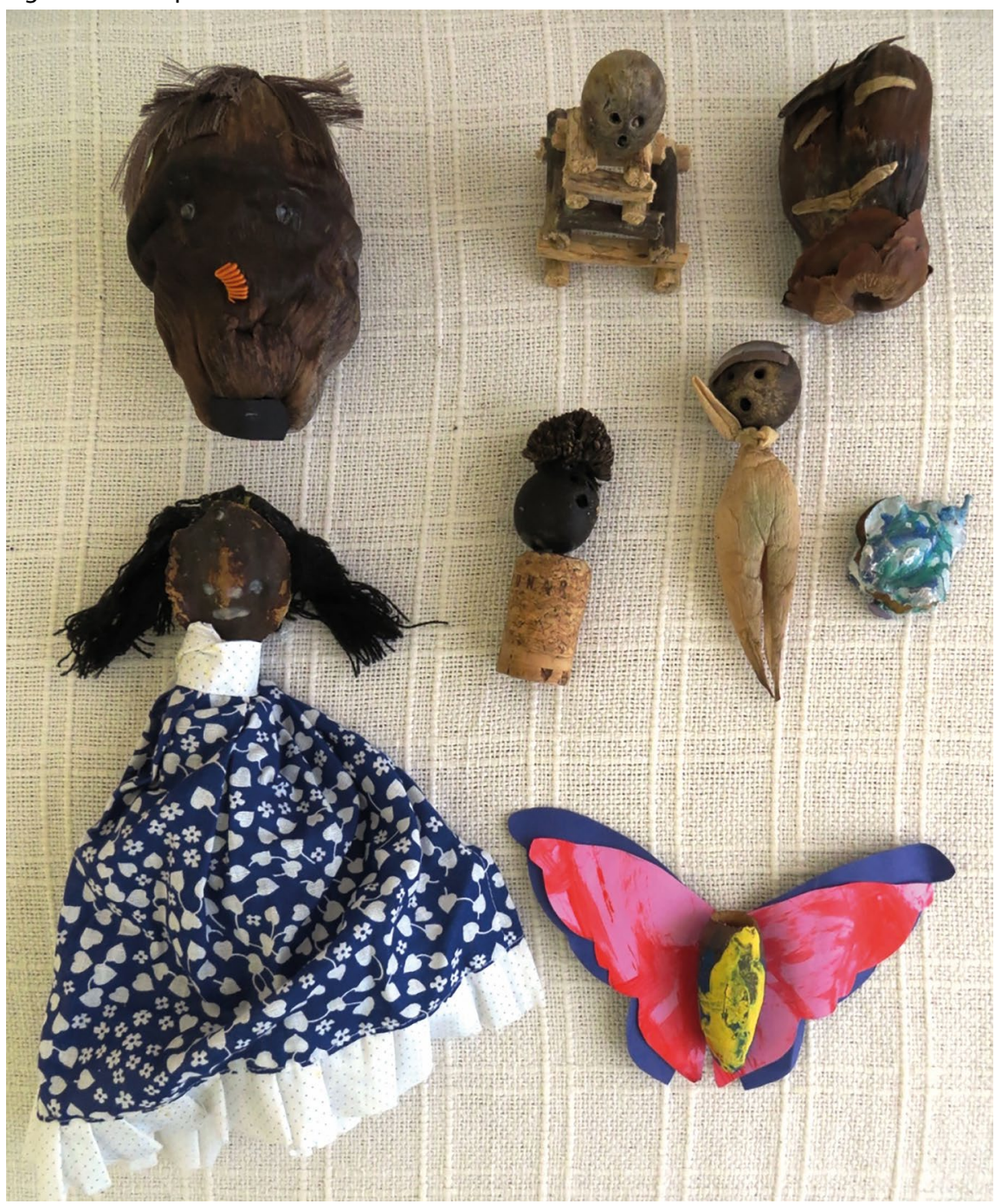

Fonte: elaboração das autoras, 2013.

\section{Considerações finais}

Neste artigo, lançamo-nos ao desafio de narrar e refletir sobre nossas práticas pedagógicas, realizadas no cotidiano plural das instituições de educação infantil.

Percebemos, nos currículos vividos, que o espaço escolar tem sido abrigo de filmes, músicas e brinquedos legitimados pela indústria do entretenimento. Seduzidos pela possibilidade de oferecer prazer e diversão às crianças, muitas vezes os 
profissionais da educação optam por passeios em buffets e shoppings em detrimento de outros espaços públicos de divertimento, como praças, bosques e parques, por exemplo. Observamos, ainda, que em muitas creches que possuem um aparelho de TV na sala de aula, este fica ligado praticamente todo o período, mantendo as crianças distraídas e ocupadas. Danças e festas organizadas para os familiares das crianças muitas vezes evidenciam uma escolha musical baseada nos hits do momento, com a repetição de gestos e coreografias prontas. O espaço do brincar muitas vezes é colonizado por personagens de desenhos animados, fantasias de super-heróis produzidos pela indústria do divertimento. Paredes, murais e espaços de exposição muitas vezes não abrigam a produção da criança; é comum vermos escolas enfeitadas sobretudo pelas mãos dos adultos e com materiais prontos disponíveis no mercado.

Quando presenciamos falas de crianças no sentido do consumir, como: "a Páscoa é o brinquedo que tem no ovo"; "meu pai vai comprar o videogame para mim"; "eu não posso emprestar meu brinquedo porque ele é novo", percebemos que as crianças estão muito mais preocupadas com a posse e a aquisição de bens, deixando de brincar com os brinquedos que construíram sozinhas ou com a ajuda de um adulto ou amigo. Preocupados em proteger dos outros o objeto que adquiriram, deixam de fantasiar nas brincadeiras e interagem menos com os amigos. Ora, o que nós profissionais da educação infantil fazemos para garantir o direito à infância face à invasão massiva das publicidades?

Pensando na responsabilidade que a escola tem com a infância, destacamos que essa instituição é o espaço da cultura como experiência e que tem como compromisso a crítica, a formação e a construção do conhecimento. A escola, assim, não é um espaço de consumo e de lazer, seu olhar para a infância e sua proposta pedagógica não devem ser referenciados na indústria do divertimento. Caberia aos profissionais das instituições de educação infantil promover experiências de socialização, práticas coletivas que se desdobrem em um fazer diferente e que permitam a reflexão sobre os modelos apresentados pela mídia, problematizando como estes são voltados à persuasão e ao consumo (KRAMER, 2000; OSTETTO, 2004).

O espaço da educação infantil é, então, aquele em que circulam culturas, tradições, costumes e valores de grupos diferentes, é o lugar das múltiplas experiências e saberes. É o espaço do singular e do plural, manifestado na dança, na música, nas festas, no cultivo dos alimentos, nos mitos e lendas que povoam o imaginário coletivo de grupos e etnias diversos (ROVERI, 2014). Desse modo, a escola tem como compromisso disponibilizar o acervo cultural de contos, lendas e brincadeiras que enriqueçam o repertório infantil, ou seja, oferecer conteúdo para a imaginação e a expressão das crianças (KISHIMOTO, 1996; KRAMER, 2000). 
Prado (1999) considera que a construção de conhecimentos não se dá apenas por meio da reprodução da realidade, mas implica uma relação ambígua de transformação de crianças e adultos, ambos seres complexos e múltiplos e que se reapropriam da própria ação, produzindo novos conhecimentos. Sendo assim, é importante que a escola proporcione o brincar e permita que as crianças experimentem, criem, conheçam e explorem as riquezas dos espaços, de seus sujeitos e de suas interações.

Consideramos os brinquedos como objetos culturais, portadores de discursos e de interpretações que revelam expectativas sociais em torno da educação das crianças. Pensar um trabalho que contemple a imaginação e a construção artesanal de um brinquedo possibilita a autoria e também a expressão de nossa própria identidade (OLIVEIRA, 1989).

Com as reflexões sobre o dia do brinquedo, buscamos contribuir para a construção de outras possibilidades de trabalho que garantam o direito à infância em seus múltiplos aspectos socioafetivos. Acreditamos que, a partir de nossas práticas pedagógicas, pudemos dar mais espaço às criações e às interações das crianças, aumentando o repertório das brincadeiras e valorizando a imaginação. Além disso, conseguimos envolver outros professores de nossas escolas e buscamos parcerias entre as turmas e as famílias. Aprendemos juntos a construir brinquedos e brincadeiras diferentes das que já conhecíamos, que nos ajudaram a superar os desejos advindos de um mundo cada vez mais permeado pelas relações de consumo.

\section{Media, consumption and advertisement: reflecting about play in childhood education}

\section{Abstract}

This article discusses the influence of advertising in childhood, fro the account of a pedagogical experience that occurred in 2013 in early childhood municipal schools of Campinas, with children from 02-06 years old. The aim of this analysis is to rethink the school function face of a massive invasion of childhood advertising, taking as analytical object the "toy day", a common practice in childhood institutions. In this work are reported some practices that contributed to children experiences childhood in its multiple languages. The purpose is not to restrict the pedagogical choices, but raise other searches for alternatives that articulate reflections about consumerism and space of play. As a result of this discussion, it is concluded that the possibilities for overcome the consumerism logic is both to provide many significant experiences for children and sensibilize the community and the school professionals.

Keywords: Childhood. Childhood education. Consumerism. Play. 


\section{Nota}

1 Esta proposta foi elaborada a partir de uma campanha organizada pelo Instituto Alana com o objetivo de refletir sobre o consumo. Foi lançada no Dia das Crianças de 2012, intitulada Feira de trocas de brinquedos. Mais informações disponíveis em: <http://feiradetrocas.alana.org.br/>. Acesso em: 10 set. 2013.

\section{Referências}

ALMEIDA, Milton José de. Histórias em imagens e sons na moderna sociedade oral: cinema e televisão. Leitura: Teoria \& Prática, Campinas, a. 30, Número Especial, p. 24-30, out. 2012.

BARTHES, Roland. Mitologias. São Paulo: Difel, 1982.

BOURDIEU, Pierre. A distinção: crítica social do julgamento. São Paulo: Edusp; Porto Alegre: Zouk, 2007.

GIROUX, Henry A. A disneyzação da cultura infantil. In: SILVA, Tomaz T. da; MOREIRA, Antonio F. (Org.). Territórios contestados: o currículo e os novos mapas políticos e culturais. Petrópolis: Vozes, 1995.

HALL, Stuart. A centralidade da cultura: notas sobre as revoluções culturais do nosso tempo. Educação \& Realidade, Porto Alegre, v. 22, n. 2, p. 15-46, jul./dez. 1997.

KISHIMOTO, Tizuko Morchida. Jogo, brinquedo, brincadeira e a educação. São Paulo: Cortez, 1996.

KRAMER, Sonia. Infância, cultura contemporânea e educação contra a barbárie. Revista Teias, Rio de Janeiro: ProPEd/UERJ, v. 1, n. 2, p. 1-14, 2000.

LINN, Susan. Crianças consumidoras: a infância roubada. São Paulo: Instituto Alana, 2006.

MARTINI, Silvia R. Modena. O IBOPE, a opinião pública e o senso comum dos anos 1950: hábitos, preferências, comportamentos e valores dos moradores dos grandes centros urbanos brasileiros (Rio de Janeiro e São Paulo). Campinas: [s. n.], 2011.

MOREIRA, Antonio Flavio Barbosa (Org.). Currículo: questões atuais. Campinas: Papirus, 1997.

OLIVEIRA, Paulo de Salles. O que é brinquedo. São Paulo: Brasiliense, 1989.

OSTETTO, Luciana Esmeralda. "Mas as crianças gostam!" Ou, sobre gostos e repertórios musicais. In: OSTETTO, Luciana Esmeralda; LEITE, Maria Isabel (Org.). Arte, infância e formação de professores: autoria e transgressão. Campinas: Papirus, 2004. p. 41-60.

PARAÍSO, Marlucy Alves (Org.). Pesquisas sobre currículos e culturas: temas, embates, problemas e possibilidades. Curitiba: CRV, 2010.

PRADO, Patrícia Dias. As crianças pequenininhas produzem cultura? Considerações sobre educação e cultura infantil em creche. Pro-Posições, Campinas, v. 10, n. 1 (28), p. 110-118, mar. 1999.

ROVERI, Fernanda Theodoro. Barbie na educação de meninas: do rosa ao choque. São Paulo: Annablume, 2012. 
. Rodopiando com o "Saci-Pererê": movimentos do brincar na educação infantil. Holos, Natal, v. 5, p. 54-63, dez. 2014. Disponível em: <http://www2.ifrn.edu.br/ojs/index.php/HOLOS/ article/view/2524>. Acesso em: 22 jan. 2015.

SCHOR, Juliet B. Nascidos para comprar: uma leitura essencial para orientarmos nossas crianças na era do consumismo. São Paulo: Gente, 2009.

SOUZA, Solange Jobim e; SALGADO, Raquel Gonçalves. A criança na idade mídia: reflexões sobre cultura lúdica, capitalismo e educação. In: SARMENTO, Manuel; GOUVEA, Maria Cristina Soares de (Org.). Estudos da infância: educação e práticas sociais. Petrópolis: Vozes, 2008. p. 207-221.

STEINBERG, Shirley R.; KINCHELOE, Joe L. Cultura infantil: a construção corporativa da infância. Rio de Janeiro: Civilização Brasileira, 2001.

TOLOTTI, Márcia. Consumistas precoces - como ensinar crianças e jovens cada vez mais seduzidos pela ideia do consumo desenfreado a serem críticos à cultura do desperdício e do endividamento? Carta Fundamental, São Paulo, n. 38, p. 16-17, maio 2012.

WEISS, Luise. Brinquedos \& engenhocas: atividades lúdicas com sucata. São Paulo: Scipione, 1997.

ZANOLLA, Silvia Rosa Silva. Indústria cultural e infância: estudo sobre a formação de valores em crianças no universo do jogo eletrônico. Educação \& Sociedade, Campinas, v. 28, n. 101, dez. 2007. Disponível em: <http://www.scielo.br/pdf/es/v28n101/a0428101.pdf>. Acesso em: 14 ago. 2013. 